\title{
MODEL ISOTERM FREUNDLICH DAN LANGMUIR OLEH ADSORBEN ARANG AKTIF BAMBU ANDONG (G. verticillata (Wild) Munro) DAN BAMBU ATER (G. atter (Hassk) Kurz ex Munro)
}

\author{
Murtihapsari, Bertha Mangallo dan Dini Dwi Handyani \\ Jurusan Kimia, Fakultas Matematika dan Pengetahuan Alam \\ Universitas Negeri Papua
}

\author{
ABSTRACT \\ Freundlich and Langmuir Isotherms Model by Active Chorcoal Adsorbent \\ Bamboo Andong (G. verticillata (Wild) Munro) and \\ Bamboo Ater (G. atter (Hassk) Kurz ex Munro)
}

\begin{abstract}
Diazinon insecticide adsorption by two types of adsorbent, namely activated charcoal bamboo andong (G. verticillata (Wild) Munro) and bamboo ater (G. atter (Hassk) Kurzex Munro) at optimum conditions determined the maximum adsorption capacity of both types of adsorbent. Data analysison the effect of concentration on the adsorption capacity was used Langmuir and Freundlich isotherms equation. It was obtained. That the curve of adsorption isotherms of the Langmuir isotherm better modeled with linear regression coefficients were relatively more approach 1 is $R^{2}=0,996$ for both types of adsorbents. Langmuir isotherm equation obtained from adsorpsi maximum capacity of activated charcoal bamboo andong (G. verticillata (Wild) Munro) of $4.630 \mathrm{mg} / \mathrm{g}\left(1,433.10^{-5} \mathrm{~mol} / \mathrm{g}\right)$ with $K=0,332(\mathrm{Kmol} / \mathrm{L})^{-1}$ and Eads at $-2,750 \mathrm{~kJ} / \mathrm{mol}$, while the activated charcoal bamboo ater (G. atter (Hassk) Kurzex Munro)produce the maximum adsorption capacity of $1,786 \mathrm{mg} / \mathrm{g}\left(5,868.10^{-6} \mathrm{~mol} / \mathrm{g}\right)$ with $\mathrm{K}=0,202(\mathrm{Kmol} / \mathrm{L})^{-1}$ and Eads $=-3,898 \mathrm{~kJ} / \mathrm{mol}$, so the adsorption of both types of adsorbents indicated experiencing a physical adsorption (physisorption / fisisorpsi).
\end{abstract}

Keyword: G. verticillata (Wild) Munro, G. atter (Hassk) Kurz ex Munro, Adsorption, Diazinon, actived charcoal

\begin{abstract}
ABSTRAK
Adsorpsi insektisida diazinon oleh dua jenis adsorben, yaitu arang aktif bambu andong (G. verticillata (Wild) Munro) dan bambu ater (G. atter (Hassk) Kurz ex Munro) pada kondisi optimum bertujuan untuk menentukan kapasitas adsorpsi maksimum dari kedua jenis adsorben. Analisis data pengaruh konsentrasi terhadap kapasitas adsorpsi digunakan persamaan isoterm Langmuir dan Freundlich. Berdasarkan data yang diperoleh, kurva isoterm adsorpsi lebih mengikuti model isoterm Langmuir dengan koefisien regresi linier yang relatif lebih mendekati 1 yaitu $\mathrm{R}^{2}=0,996$ untuk kedua jenis adsorben. Dari persamaan isoterm Langmuir diperoleh kapasitas adsorpsi maksimum arang aktif bambu andong (G. verticillata (Wild) Munro) sebesar 4,630 $\mathrm{mg} / \mathrm{g}\left(1,433.10^{-5} \mathrm{~mol} / \mathrm{g}\right)$ dengan $K=0,332(\mathrm{Kmol} / \mathrm{L})^{-1}$ dan Eads sebesar $-2,750 \mathrm{~kJ} / \mathrm{mol}$, sedangkan arang aktif bambu ater $(G$. atter (Hassk) Kurz ex Munro) menghasilkan kapasitas adsorpsi maksimum sebesar 1,786 mg/g $\left(5,868.10^{-6} \mathrm{~mol} / \mathrm{g}\right)$ dengan $K=0,202(\mathrm{Kmol} / \mathrm{L})^{-1}$ dan $\mathrm{E}_{\text {ads }}=-3,898 \mathrm{~kJ} / \mathrm{mol}$, sehingga adsorpsi kedua jenis adsorben diindikasikan mengalami adsorpsi secara fisik (physisorption/ fisisorpsi).
\end{abstract}

Kata kunci : G. verticillata (Wild) Munro, G. atter (Hassk) Kurz ex Munro Adsorpsi, Diazinon, Arang aktif

\section{PENDAHULUAN}

Diazinon merupakan salah satu insektisida golongan organofosfat yang digunakan untuk membasmi kutu, ngengat, kecoa dan tungau. Diazinon banyak digunakan dalam bidang pertanian, perkebunan dan kehutanan. Diazinon mempengaruhi sistem saraf dengan menghambat aktivitas enzim kolinesterase. Diazinon mudah terserap oleh kulit dan bersifat sinergis dengan racun lainnya. Keracunan diazinon pada manusia dapat menyebabkan iritasi pada kulit, sakit kepala, berkeringat, gelisah, kehilangan konsentrasi, mual, muntah, denyut jantung melemah, sakit perut, diare, pingsan, koma 
dan kematian (Anonim, 2008), oleh karena itu residu insektisida perlu dikendalikan.

Beberapa material adsorben yang dapat digunakan dalam adsorpsi residu insektisida adalah zeolit, arang aktif, abu sekam, dan bentonit. Arang aktif bambu memilki luas permukaan berpori yang lebih besar dibandingkan dengan arang kayu yaitu lebih dari $1000 \mathrm{~m}^{2} / \mathrm{g}$ (Anonim, 2010). Arang aktif bambu ater memiliki karakteristik arang aktif yang memenuhi Standar Nasional Indonesia (SNI) (Krisdiantoro et al. 2006). Arang aktif bambu memilki kapasitas adsorpsi terhadap metilen blue dengan kapasitas adsorpsi maksimum 454,2 mg/g (Hameed et al. 2006). Arang aktif bambu andong ( $G$. verticillata (Wild) Munro) dan bambu betung ( $G$. aspera (Schultes F) Kurtz) memilki kapasitas adsorpsi yang lebih tinggi yaitu $1.150 \mathrm{mg} / \mathrm{g}$ dan $1.004 \mathrm{mg} / \mathrm{g}$ terhadap iodine dibandingkan dengan arang aktif yang berasal dari tempurung kelapa dan bakau (Krisdiantoro et al. 2006).

Penelitian ini bertujuan untuk mengkaji kemampuan adsorpsi arang aktif bambu andong ( $G$. verticillata (Wild.) Munro) dan bambu ater (G.atter (Hassk) Kurz ex Munro) terhadap diazionin dengan persamaan isoterm adsorpsi Langmuir dan Freundlich.

\section{BAHAN DAN METODE}

\section{Bahan dan Peralatan yang Digunakan}

Bahan yang digunakan dalam penelitian ini meliputi ; batang bambu andong (G. verticillata (Wild) Munro) dan ater ( $G$. atter (Hassk) Kurz ex Munro) yang berasal dari daerah Amban Kabupaten Manokwari, pestisida diazinon 60 EC (diazinon $600 \mathrm{~g} / \mathrm{L}$ ), kertas saring Whatman 42 , dan aquades.

Alat - alat yang digunakan meliputi seperangkat alat - alat gelas, timbangan analitik, Neraca OHAUS, saringan ayakan (mesh 100), Tungku pembuat arang, oven, tanur, eksikator, shaker dan spektroskopis UV-vis merk Milton Roy Array 3000.

\section{Pembuatan arang aktif (Haniko, 2010)}

Proses pembuatan arang dilakukan dengan menggunakan tungku pemanas yang terbuat dari wadah besi. Potongan bambu dimasukkan ke dalam wadah yang telah dilubangi bagian tutupnya, selanjutnya bambu tersebut dinyalakan hingga mengeluarkan asap. Lubang (ventilasi) dibagian penutup wadah dibiarkan terbuka agar menjadi saluran keluarnya asap. Ketika asap yang keluar berwarna kebiru - biruan, ventilasi ditutup dan dibiarkan selama 6 jam untuk pengarangan bambu ater ( $G$. atter (Hassk) Kurz ex Munro) dan 8 jam untuk pengarangan bambu andong ( $G$. verticillata (Wild) Munro). Arang yang dihasilkan setelah dingin kemudian dicuci dengan menggunakan aquades dan dikeringkan dengan menggunakan oven pada temperatur $100^{\circ} \mathrm{C}$ selama 1 jam. Pada tahap akhir arang diaktivasi secara fisik melalui pemanasan pada temperatur 300 , 350 , dan $400^{\circ} \mathrm{C}$ dengan variasi waktu masing - masing temperatur selama 15 dan 30 menit. Arang aktif kemudian digerus menggunakan lumpang porselin lalu diayak dengan ukuran 100 mesh.

\section{Penentuan rendemen (SNI 01-1682- 1996)}

Rendemen arang aktif ditetapkan dengan menghitung perbandingan berat arang aktif hasil aktivasi terhadap berat arang tanpa teraktivasi.

\section{Pembuatan larutan diazinon}

Larutan formulasi diazinon $600 \mathrm{~g} / \mathrm{L}$ diencerkan dalam aquades, dibuat konsentrasi $5 \mathrm{mg} / \mathrm{L}, 10 \mathrm{mg} / \mathrm{L}, 25 \mathrm{mg} / \mathrm{L}, 50$ $\mathrm{mg} / \mathrm{L}, 75 \mathrm{mg} / \mathrm{L}$ dan $100 \mathrm{mg} / \mathrm{L}$.

\section{Penentuan konsentrasi optimum}

Sebanyak 0,5 g arang aktif dimasukkan ke dalam setiap erlenmeyer kemudian di tambahkan $100 \mathrm{ml}$ diazinon dengan variasi konsentrasi tertentu, lalu diaduk menggunakan shaker selama waktu kontak optimum, kemudian disaring menggunakan kertas saring. Variasi 
konsentrasi diazinon yang digunakan adalah $5 \mathrm{mg} / \mathrm{L}, 10 \mathrm{mg} / \mathrm{L}, 25 \mathrm{mg} / \mathrm{L}, 50$ $\mathrm{mg} / \mathrm{L}, 75 \mathrm{mg} / \mathrm{L}$ dan $100 \mathrm{mg} / \mathrm{L}$. Filtrat yang dihasilkan kemudian diukur absorbansinya menggunakan spektroskopis UV-Vis pada $\lambda_{\text {mak }} 280 \mathrm{~nm}$ untuk mengetahui konsentrasi diazinon setelah teradsorpsi oleh arang aktif (Wijayanti, 2009).

\section{Analisis Data}

Analisis data dilakukan dengan menentukan kadar akhir diazinon setelah melalui proses adsorpsi dari konsentrasi adsorbat terhadap kapasitas adsorpsi. Hasil tersebut kemudian dianalisis menggunakan persamaan isoterm Langmuir dan Freundlich untuk menentukan model isoterm adsorpsi pada adsorben.

Persamaan isoterm adsorpsi Langmuir (Zahroh, 2010) :

$\mathrm{Q}=\frac{\mathrm{b} \cdot \mathrm{K} \cdot \mathrm{Ce}}{1+\mathrm{K} \cdot \mathrm{Ce}}$

Persamaan di atas dapat diturunkan secara linier menjadi :

$\frac{\mathrm{Ce}}{\mathrm{Q}}=\frac{1}{K \mathrm{~b}}+\frac{1}{\mathrm{~b}} \mathrm{C}$

Keterangan :

$\mathrm{C}_{\mathrm{e}}=$ konsentrasi kesetimbangan adsorbat dalam larutan setelah adsorpsi ( $\mathrm{mg} / \mathrm{L})$

Q $\quad=$ jumlah adsorbat teradsorpsi per bobot adsorben $(\mathrm{mg} / \mathrm{g})$

$K=$ konstanta kesetimbangan adsorpsi (L/mg)

B = kapasitas adsorpsi maksimum dari adsorben $(\mathrm{mg} / \mathrm{g})$

Persamaan isoterm adsorpsi Freundlich (Rahmalia et al. 2009) :

$\mathrm{Q}=\mathrm{k} \cdot \mathrm{Ce} \mathrm{e}^{1 / \mathrm{n}}$

Persaman diatas dapat diubah kedalam bentuk linier dengan mengambil bentuk logaritmanya : $\log \mathrm{Q}=\underset{\operatorname{Ce} \ldots \ldots \ldots \ldots(2.4)}{\log } \quad \mathrm{k} \quad 1 / \mathrm{n} \quad \log$

Keterangan :

$\mathrm{C}_{\mathrm{e}}=$ konsentrasi kesetimbangan adsorbat dalam larutan setelah adsorpsi (mg/L)

$\mathrm{k} \quad=$ konstanta adsorpsi Freundlich

$\mathrm{n} \quad=$ konstanta empiris

$\mathrm{Q}=$ jumlah adsorbat teradsorpsi per bobot adsorben $(\mathrm{mg} / \mathrm{g})$

\section{HASIL DAN PEMBAHASAN}

Proses pembuatan arang aktif bambu andong ( $G$. verticillata (Wild) Munro) dan bambu ater (G. atter (Hassk) Kurz ex Munro) dilakukan melalui dua tahap. Pertama yaitu tahap karbonisasi, dimana kedua jenis bambu tersebut diarangkan secara terpisah menggunakan tungku pemanas dengan sistem tertutup sehingga memungkinkan tidak terjadi proses oksidasi yang dapat menyebabkan arang menjadi abu. Tahap kedua yaitu pengaktifan kedua jenis arang melalui aktivasi secara fisik menggunakan temperatur tinggi serta waktu aktivasi yang divariasikan.

\section{Rendemen}

Rendemen tertinggi terdapat pada arang aktif temperatur $300^{\circ} \mathrm{C}$ selama 15 menit dan terendah terdapat pada arang aktif dengan temperatur $400^{\circ} \mathrm{C}$ selama 30 menit, sedangkan untuk sampel arang aktif bambu ater ( $G$. atter (Hassk) Kurz ex Munro) rendemen berkisar antara 54,6$80,2 \%$. Rendemen arang aktif dipengaruhi oleh waktu dan temperatur aktivasi. Peningkatan temperatur dan waktu aktivasi yang digunakan mampu menurunkan rendemen arang aktif yang dihasilkan.

\section{Konsentrasi Optimum}

Konsentrasi optimum diazinon yang teradsorpsi oleh arang aktif bambu andong ( $G$. verticillata (Wild) Munro) adalah 22,163 mg/L dengan kapasitas adsorpsi sebesar $4.433 \mathrm{mg} / \mathrm{g}$, sedangkan 
arang aktif bambu ater (G. atter (Hassk) Kurz ex Munro) mencapai konsentrasi optimum diazinon sebesar $8,476 \mathrm{mg} / \mathrm{L}$ dengan kapasitas adsorpsi sebesar 1,695 $\mathrm{mg} / \mathrm{g}$. Pada kedua jenis adsorben tersebut terjadi penurunan kapasitas adsorpsi diatas konsentrasi optimum, hal ini disebabkan oleh lapisan luar arang aktif telah jenuh dengan diazinon sehingga adsorben tidak dapat lagi menjerap melekul - molekul diazinon lainnya (Widhianti, 2010).

Optimasi konsentrasi diazinon dapat diketahui bahwa pada konsentrasi 5 $\mathrm{mg} / \mathrm{L}$ sampai dengan $50 \mathrm{mg} / \mathrm{L}$ terjadi kenaikan kapasitas adsorpsi arang aktif bambu andong ( $G$. verticillata (Wild) Munro) dan pada arang aktif bambu ater (G. atter (Hassk) Kurz ex Munro) terjadi peningkatan kapasitas adsorpsi pada konsentrasi $5 \mathrm{mg} / \mathrm{L}$ sampai dengan 75 $\mathrm{mg} / \mathrm{L}$ (Gambar 1). Hal ini dikarenakan semakin tinggi konsentrasi larutan diazinon maka semakin banyak molekul diazinon yang bertumbukan dan berinteraksi dengan adsorben, sehingga kemampuan adsorpsinya meningkat (Widhianti, 2010).

Porositas adsorben dapat mempengaruhi daya adsorpsi suatu adsorben. Adsorben dengan porositas yang besar mempunyai kemampuan menyerap yang lebih tinggi dibandingkan dengan adsorben yang memiliki porositas kecil (Khasanah, 2009). Arang aktif bambu andong memiliki daya adsorpsi yang lebih tinggi dibandingkan dengan arang aktif bambu ater karena pembentukan porositas yang lebih besar.

\section{Penentuan Kurva Standart Diazinon}

Struktur molekul diazinon memiliki gugus kromofor $(\mathrm{N}=\mathrm{C}, \mathrm{C}=\mathrm{C}, \mathrm{S}$ $=\mathrm{P}$ ) yang merupakan gugus atau atom dalam senyawa organik yang mampu menyerap senyawa UV dan visible, selain itu terdapat tiga gugus auksokrom $\mathrm{O}^{-}$yang memberikan transisi $n \rightarrow \pi^{*}$, dimana pada transisi tersebut menyerap pada range panjang gelombang antara $200-700 \mathrm{~nm}$.

Penentuan konsentrasi diazinon dalam sampel dapat dilakukan dengan menggunakan kurva kalibrasi hubungan antara absorbansi terhadap konsentrasi larutan standar. Hal ini sesuai dengan Hukum Lambert-Beer yang menyatakan bahwa jumlah energi cahaya yang diserap (absorbansi) adalah sebanding dengan konsentrasi (C) (Anonim, 2009).

Arang aktif yang telah diaktivasi diuji kemampuan adsorpsinya terhadap diazinon dengan berbagai perlakuan waktu dan suhu aktivasi. Hasil pengukuran absorbansi dari masing - masing jenis filtrat yang dihasilkan setelah proses adsorpsi kemudian dimasukkan dalam persamaan garis lurus dari kurva standar $\mathrm{y}=0,0972 \mathrm{x}-0,0637$ dengan koefisien regresi linier $r=0,999$ akhirnya akan diperoleh konsentrasi akhir dazinon.

Persamaan isoterm Langmuir dan Freundlich di atas, terlihat bahwa adsorpsi diazinon dari kedua jenis adsorben lebih mengikuti model isoterm adsorpsi Langmuir (Gambar 3), dibuktikan dengan harga koefisien relasi $\left(\mathrm{R}^{2}\right)$ yang lebih mendekati 1 (Pranoto et. al 2003) dibandingkan model Freundlich (Gambar 4), sehingga dapat diasumsikan bahwa adsorpsi diazinon yang terjadi pada permukaan adsorben arang aktif bambu andong (G. verticillata (Wild) Munro) dan bambu ater (G. atter (Hassk) Kurz ex Munro) bersifat homogen dan adsorbat teradsorpsi dalam bentuk tunggal (monolayer).

Langmuir menggambarkan bahwa pada permukaan adsorben terdapat sejumlah tertentu sisi aktif yang sebanding dengan luas permukaan. Pada setiap sisi aktif hanya ada satu molekul yang dapat diadsorpsi (Khoirunnisa, 2005). 


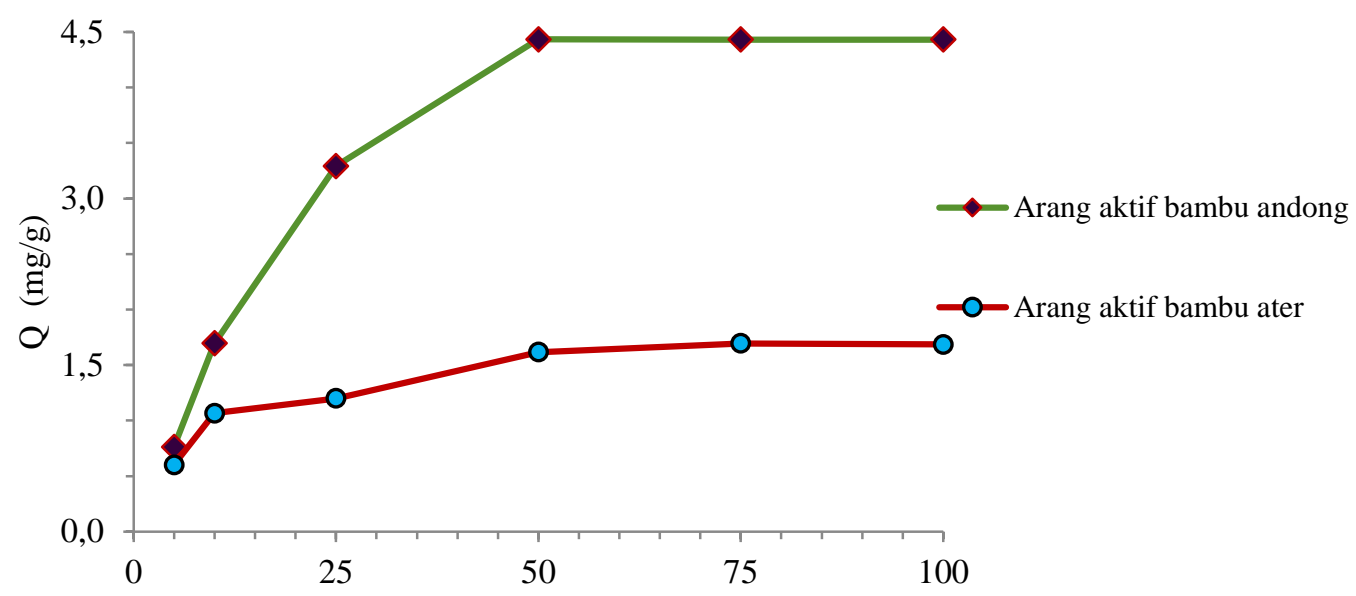

Konsentrasi (mg/L)

Gambar 1. Grafik hubungan variasi konsentrasi terhadap kapasitas adsorpsi

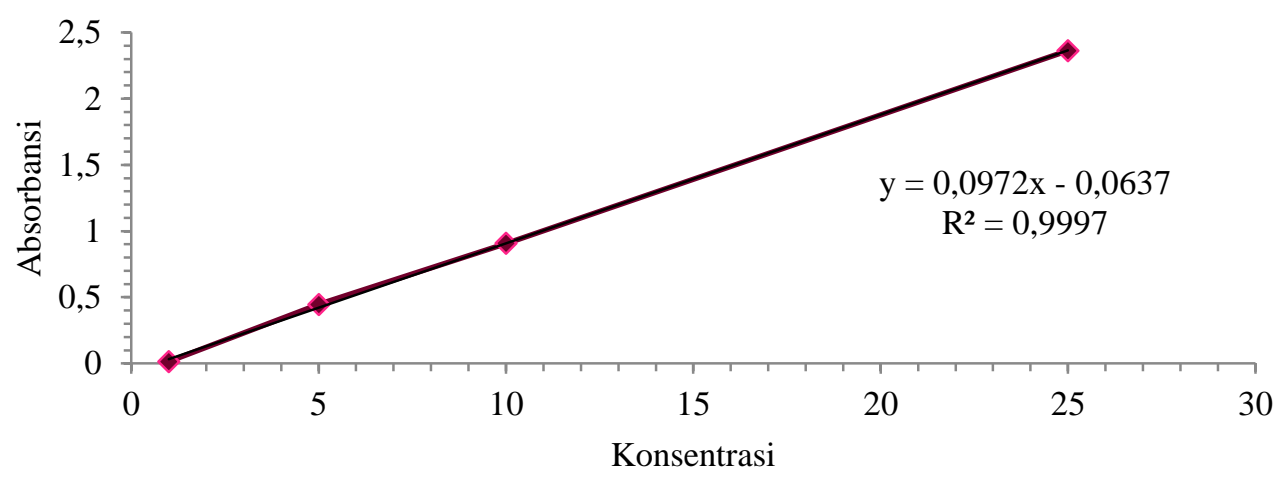

Gambar 2. Kurva standar diazinon

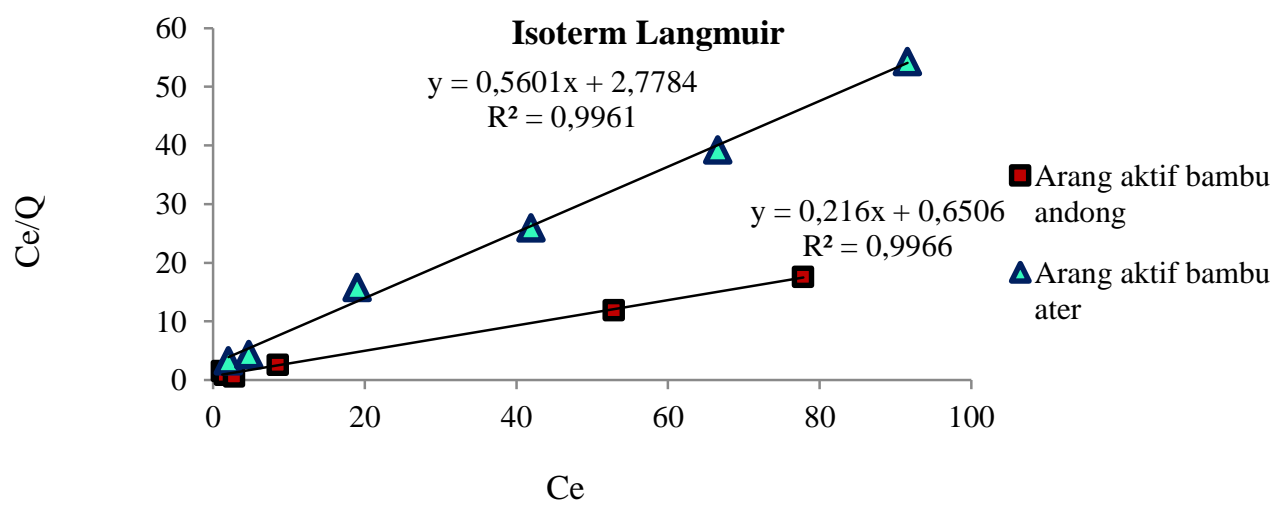

Gambar 3. Grafik persamaan isoterm Langmuir 


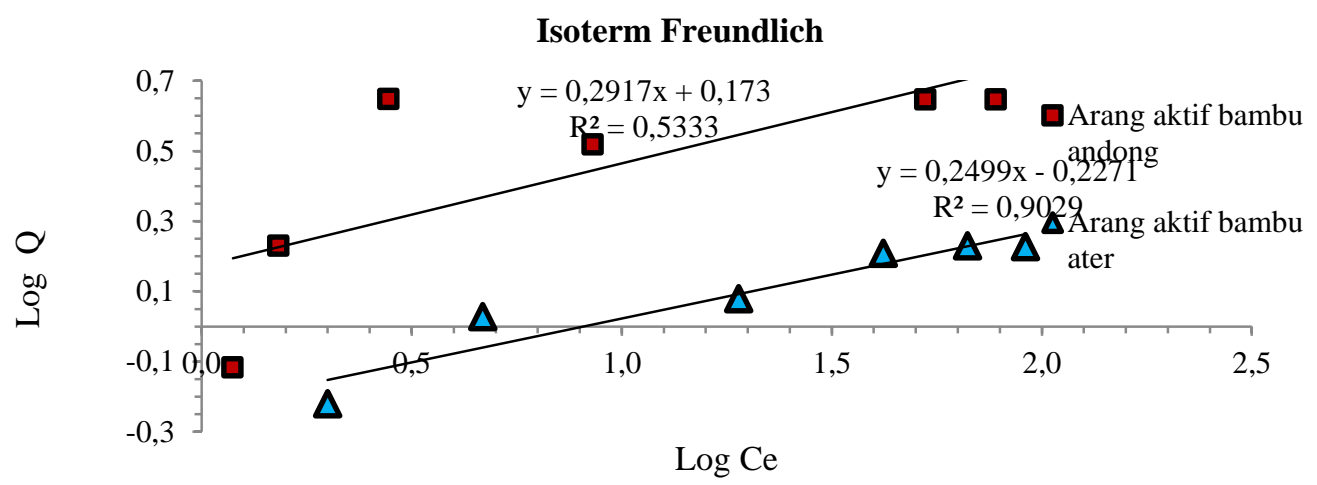

Gambar 4. Grafik persamaan isoterm Freundlich.

\section{KESIMPULAN DAN SARAN}

\section{Kesimpulan}

Kapasitas adsorpsi maksimum diazinon oleh arang aktif bambu andong ( $G$. verticillata (Wild) Munro) adalah $4,630 \mathrm{mg} / \mathrm{g}$ atau $1,433.10^{-5} \mathrm{~mol} / \mathrm{g}$ dan arang aktif bambu ater (G. atter (Hassk) Kurz ex Munro) adalah $1,786 \mathrm{mg} / \mathrm{g}$ atau $5,868.10^{-6} \mathrm{~mol} / \mathrm{g}$.

Adsorben arang aktif bambu andong (G. verticillata (Wild) Munro) dan bambu ater (G. atter (Hassk) Kurz ex Munro) mencapai linearitas tertinggi pada kurva plot $\mathrm{C}_{\mathrm{e}} / \mathrm{Q}$ terhadap $\mathrm{C}_{\mathrm{e}}$ dengan $\mathrm{R}^{2}=$ 0,996 pada isoterm Langmuir sedangkan linearitas yang dicapai pada isoterm Freundlich oleh adsorben arang aktif bambu andong (G. verticillata (Wild) Munro) adalah $\mathrm{R}^{2}=0,553$ dan $\mathrm{R}^{2}=0,902$ untuk adsorben arang aktif bambu ater $(G$. atter (Hassk) Kurz ex Munro).

\section{Saran}

Perlu dikaji model isotherm adsorpsi lainnya mengenai beberapa jenis adsorben dengan beragam variabel dan parameter.

\section{DAFTAR PUSTAKA}

Anonim. 2008. Ekstensi toksikologi diazinon. Jakarta : Badan Zat Beracun dan Penyakit Registry,
Divisi Toksikologi Lingkungan dan Kedokteran.

Anonim. 2009. Alat analisa (pengantar praktikum instrumen). Surakarta: Jurusan Fakultas Teknik, Universitas Sebelas Maret.

Anonim. 2009. Jenis pestisida. http://www.dgwibawa.awardspac e.com (15 juli 2009) PT. Darma Guna Wibawa.

Anonim. 2010. Karbon Aktif. http://www.wikipedia.com/karbo n-aktif (26 Januari 2011).

Hameed BH, Din ATM, Ahmad AL. 2006. Adsorption of methylene blue into bamboo-based activated carbon : kinetics and equilibrium studies. J Elsevier B.V. All rights reserved.

Haniko S. 2010. Studi adsorpsi ion $\mathrm{Ca}^{2+}$ menggunakan adsorben arang kayu matoa (Pometia pinnata) untuk menurunkan kesadahan air [skripsi]. Manokwari : Fakultas Matematika dan Ilmu Pengetahuan Alam, Universitas Negeri Papua.

Khasanah EN. 2009. Adsorpsi logam berat. Oseana, Vol. XXIV No. 4 : $1-7$ 
Khoirunnisa F. 2005. Kajian adsorpsi dan desorpsi $\mathrm{Ag}\left(\mathrm{S}_{2} \mathrm{O}_{3}\right)_{2}{ }^{3-}$ dalam limbah fotografi pada dan dari adsorben kitin dan asam humat terimobilisasi pada kitin [Tesis]. Yogyakarta : Jurusan Ilmu Kimia Fakultas Matematika dan Pengetahuan Alam Program Pasca Sarjana Universitas Gajah Mada.

Krisdiantoro, Sumarni G, Ismanto A. 2006. Sari hasil penelitian bambu. http://www.dephut.go.id/index.p hp?q=id/node/1241 $[22$ November 2006]

Pranoto, Masykur A, Mawahib SAS. 2003. Penurunan kadar timbal dan zat warna tekstil dalam larutan dengan menggunakan karbon aktif bagasse. Jurusan Kimia FMIPA Universitas Sebelas Maret Surakarta. Enviro 2 (1) : 9-16, ISSN : 1411 - 4402

Rahmalia W, Yulistira F, Ningrum J, Qurbaniah M, Ismadi M. 2009. Pemanfaatan potensi tandan kosong kelapa sawit (Elais guineensis Jacq) sebagai bahan dasar c-aktif untuk adsorpsi logam perak dalam larutan. Pontianak : Jurusan Kimia, Fakultas Matematika dan Ilmu Pengetahuan Alam Universitas Tanjungpura

Widhianti W. D. 2010. Pembuatan arang aktif dari biji kapuk (Ceiba pentandra L.) sebagai adsorben zat warna rhodamin $B$ [skripsi]. Surabaya : Fakultas Sains dan Teknologi, Univesitas Airlangga.

Wijayanti R. 2009. Arang aktif dari ampas tebu sebagai adsorben pada pemurnian minyak goreng bekas [skripsi]. Bogor : Fakultas MIPA, Institut Pertanian Bogor.

Zahroh W. 2010. Kajian kesetimbangan adsorpsi Cr (VI) pada biomassa kangkung air (Ipomoea aquatica Forsk) [skripsi]. Malang : Jurusan Kimia, Fakultas Sains dan Teknologi, Universitas Islam Negeri (UIN) Maulana Malik Ibrahim. 